\title{
INTERPRETATION OF PEAK OXYGEN CONSUMPTION IN 10-12-YEAR-OLD SOCCER PLAYERS: EFFECT OF BIOLOGICAL MATURATION AND BODY SIZE
}

\author{
Urmo Vitckberg, Pritt Purge, Toivo Jürimäe, \\ Meeli SaAr, Evelin LätT, Jarek Mäestu, JaAk Jürimäe \\ Institute of Sport Pedagogy and Coaching Sciences, \\ Centre of Behavioural and Health Sciences, University of Tartu, Tartu, Estonia
}

\begin{abstract}
The aim of this study was to investigate the effect of biological maturation and body size on aerobic capacity using appropriate scaling procedures in 10-12-year-old soccer players divided into late, average and early maturing boys. Peak oxygen consumption $\left(\mathrm{VO}_{2}\right.$ peak) was expressed as absolute values, ratio standards, theoretical exponents and experimentally observed exponents. $\mathrm{VO}_{2}$ peak was not directly proportional to body mass as the experimentally observed exponent for body mass calculated through linear regression analysis yielded to $b=0.64\left(R^{2}=0.62 ; p<0.05\right)$. The $95 \%$ confidence interval for the experimentally calculated body mass-related exponent ( $95 \% \mathrm{CI}: 0.51$ to $0.77)$ included the theoretical values of the exponents $(b=0.67$ and $b=0.75)$. $\mathrm{VO}_{2}$ peak expressed in $1 /$ min was different $(\mathrm{p}<0.05)$ between groups with contrasting maturity status. When $\mathrm{VO}_{2}$ peak values were adjusted for body mass $(\mathrm{ml} / \mathrm{min} / \mathrm{kg})$, or when the effect of body mass was adjusted for using theoretical exponent scales $\left(\mathrm{ml} / \mathrm{kg}^{0.67} / \mathrm{min}, \mathrm{ml} / \mathrm{kg}^{0.75} / \mathrm{min}\right)$ and experimentally observed exponent $\left(\mathrm{ml} / \mathrm{kg}^{0.64} / \mathrm{min}\right)$, the $\mathrm{VO}_{2}$ peak responses displayed relativeley constant values $(\mathrm{p}>0.05)$ throughout different maturation groups. Linear regression analyses indicated that after adjusting for the effects of body mass using the theoretical exponent scales $\left(\mathrm{ml} / \mathrm{min} / \mathrm{kg}^{0.67}\right)$, biological maturation and body size had no effect on $\mathrm{VO}_{2}$ peak values in young soccer players. In conclusion, the theoretical exponent scale for body mass $\left(\mathrm{ml} / \mathrm{kg}^{0.67} / \mathrm{min}\right)$ control adequately for biological maturation and body size differences in $\mathrm{VO}_{2}$ peak
\end{abstract}


in 10-12-year-old soccer players. Therefore, more mature soccer players with better body size values should not be preferentially selected for young soccer teams.

Keywords: soccer; boys; aerobic capacity; maturity status; allometric scaling

\section{INTRODUCTION}

Performance in soccer is related to various maturity $[5,10]$, anthropometric $[5$, $14]$, technical [11], psychological [5] and physiological [3, 4] parameters in young soccer players. Soccer is a sport, where approximately $90 \%$ of energetic demand is estimated to be covered by aerobic metabolism [8]. Peak oxygen consumption $\left(\mathrm{VO}_{2}\right.$ peak $)$ appears to be the best index of aerobic capacity in soccer players $[4,8]$. A significant relation between $\mathrm{VO}_{2}$ peak and a distance covered during a soccer match, and a rank order correlation between $\mathrm{VO}_{2}$ peak and placement in the league have been found [8]. Therefore, $\mathrm{VO}_{2}$ peak plays an important role in soccer match, influencing technical performance and tactics in young soccer players [3].

While aerobic capacity in adult soccer players has been described by various studies $[3,8]$, published data on the effects of growth and maturation on $\mathrm{VO}_{2}$ peak are limited and conflicting [4]. It has been found that aerobic capacity increases progressively from eight to 18 years of age [18]. Participation in young soccer teams is primarily based on chronological age groups, which often may span up to two years [5] and biological maturation within this two years age span may differ considerably in boys reaching puberty. Therefore, possible interaction between biological maturation and the development of aerobic capacity could be overlooked. More mature soccer players often have greater aerobic capacity values than their less mature peers $[3,19]$ and there are studies to suggest that biological maturation affects the development of $\mathrm{VO}_{2}$ peak in children $[1,10]$.

Different studies have demonstrated that early maturing children have advantages over late maturing children in various anthropometric characteristics (e.g., height, leg length, body mass), which in turn may influence different physiological performance parameters [5, 14, 16]. Furthermore, even on these physiological parameters that have scaled for body dimensions, such as relative strength [6] and $\mathrm{VO}_{2}$ peak [4], more mature soccer players perform better in comparison with less mature peers. The superior physiological performance associated with advanced maturity among pubertal boys may also be identified as having superior ability by coaches and peers [5]. Scaling of physi- 
ological performance parameters to body dimensions has been suggested to use to reduce the effect of maturity status $[4,19]$. In an attempt to allow for the comparison of $\mathrm{VO}_{2}$ peak values in young soccer players with different maturity status and body sizes, allometric scaling has been adopted [4, 19]. According to Chamari et al. [3], $\mathrm{VO}_{2}$ peak should be expressed in relation to body mass raised to the power of $0.72-0.94$ over a wide range of body mass depending on the group investigated. Theoretical exponents of 0.67 and 0.75 have also been used to adjust for the body mass effect on $\mathrm{VO}_{2}$ peak in adolescent soccer players [4]. However, to our best of knowledge, there are no studies performed that have investigated the effects of theoretical exponents and experimentally observed exponents to adjust for the body mass effects on $\mathrm{VO}_{2}$ peak in younger soccer players. Accordingly, the purpose of the present investigation was to evaluate different methods used to adjust the $\mathrm{VO}_{2}$ peak data to compensate for biological maturation and body size in boys with different maturity status.

\section{MATERIALS AND METHODS}

\section{Participants}

Sixty-four young soccer players volunteered to participate in this study. They were recruited from local training groups and had a training history of $4.5 \pm 1.5$ years and had trained for $4.6 \pm 1.6 \mathrm{~h}$ per week for at least last two years. Data for participants included chronological age, skeletal age, predicted age at peak height velocity, pubertal development (Tanner stages), anthropometry, and $\mathrm{VO}_{2}$ peak. None of the participants was receiving any medications or had any disease. All procedures were approved by the Medical Ethics Committee of the University of Tartu and explained to the children and their parents who signed a consent form.

\section{Anthropometry and biological maturation}

Body height $(\mathrm{cm})$ and sitting height $(\mathrm{cm})$ were measured with the use of a Martin metal anthropometer to the nearest $0.1 \mathrm{~cm}$ acccording to the standard technique, and body mass was measured with minimal clothing to the nearest $0.05 \mathrm{~kg}$ with a medical electronic scale (A\&D Instruments, Abingdon, UK). BMI was calculated as body mass $(\mathrm{kg})$ divided by body height $\left(\mathrm{m}^{2}\right)$.

Chronological age (CA) was calculated as the difference between the date of birth and the date on which the radiograph was taken. Skeletal age (SA) was assessed with an X-ray of the left hand and wrist, and determined according 
to the method of Greulich and Pyle [7]. Pubertal development of the participants was assessed by self-report using an illustrated questionnaire of pubertal stages according to the criteria of Tanner [20]. Pubertal development assessment according to the method of Tanner, which uses self-assessment of genitalia and pubic hair stage in boys, has been validated previously [13] and used in our previous studies with boys $[9,17]$. The boys were given photographs, figures and descriptions, and were asked to choose the one figure that most accurately reflected their appearance. In case of discrepancies between the two variables (genitalia development and pubic hair stage), greater emphasis was placed on the degree of genitalia development. Predicted age at peak height velocity (APHV) of the participants was estimated using CA, body height, sitting height, and body mass data [2].

The difference between SA and CA (SA-CA) was calculated as an estimate of relative SA [5]. All participants were divided into three groups based on the difference between SA and CA [5]. Late maturing (LM) had SA younger than CA by $>0.5$ years, average maturing $(\mathrm{AM})$ had $\mathrm{SA} \pm 0.5$ years $\mathrm{CA}$, and early maturing $(\mathrm{EM})$ had $S A$ older than CA by $>0.5$ years. In addition, soccer players were grouped by $\mathrm{CA}$ and by pubertal development [4].

\section{Peak oxygen consumpion and allometric scaling}

Peak oxygen consumption was measured on an electronically braked cycle ergometer (Lode Corival, Netherlands). Parcipants performed an initial work rate of $50 \mathrm{~W}$ with an increments of $25 \mathrm{~W}$ every $3 \mathrm{~min}$. Parcipants cycled at a cadence of $70 \pm 5 \mathrm{rpm}$, and they were actively encouraged to continue until volutional exhausion. Heart rate (HR) was recorded every $5 \mathrm{~s}$ during the test using a commercially available HR monitor (Polar S 725X, Polar Electro, Kempele, Finland). Gas exchange variables were measured throughout the test in a breath-by-breath mode and data were stored in 10 s intervals. Oxygen consumption $\left(\mathrm{VO}_{2}\right)$, carbon dioxide output $\left(\mathrm{VCO}_{2}\right)$ and minute ventilation $\left(\mathrm{V}_{\mathrm{E}}\right)$ were continuously measured using portable open spirometry system (MetaMax 3B, Cortex, Leipzig, Germany). The analyser was calibrated with gases of known concentration before each test according to the manufacturer's guidelines. All data were calculated by means of computer analysis using standard software (MetaMax-Analysis 3.21, Cortex, Leipzig, Germany). Peak oxygen consumption was achieved when two of the following three criteria were fullfilled: 1) $\mathrm{VO}_{2}$ plateau defined as a failure of $\mathrm{VO}_{2}$ to increase by greater than $2.0 \mathrm{ml} / \mathrm{kg} / \mathrm{min}$ with increase of test load;2) $\mathrm{HR} \geq 95 \%$ from the predicted 
individual maximum (formula 220-age); and 3) respiratory exchange ratio $\geq 1.05$ [15].

In addition to absolute values ( $1 / \mathrm{min}), \mathrm{VO}_{2}$ peak was expressed as a ratio standard for body mass ( $\mathrm{ml} / \mathrm{kg} / \mathrm{min}) . \mathrm{VO}_{2}$ peak was also adjusted for body mass using allometric scaling with theoretical exponents of $0.67\left(\mathrm{ml} / \mathrm{kg}^{0.67} / \mathrm{min}\right)$ and $0.75\left(\mathrm{ml} / \mathrm{kg}^{0.75} / \mathrm{kg}\right)$ [4]. Finally, the experimentally observed exponent was calculated according to allometric relationship between body size and $\mathrm{VO}_{2}$ peak, which is based on the general allometric equation $\left(\mathrm{y}=\mathrm{ax}{ }^{\mathrm{b}}\right)$, where $\mathrm{y}$ can take the absolute value of $\mathrm{VO}_{2}$ peak, $\mathrm{x}$ is the body mass in $\mathrm{kg}$, a is the proportionality constant, and $\mathrm{b}$ is the exponent for body mass. This can be described by the following equation $\log _{y}=\log _{a+b} x \log _{x}[3,4,19]$.

\section{Statistical analysis}

Statistical analysis was performed with SPSS 17.0 for Windows (Chicago, IL, USA). Means and $\pm S D$ were determined. Evaluation of normality was performed with the Shapiro-Wilk statistical method. One-way analyses of variance with LSD post hoc tests were used to evaluate differences between groups. Spearman correlation analysis was used to assess the relationships of biological maturation and body size variables with different $\mathrm{VO}_{2}$ peak values. Multiple linear regression analyses were performed to identify the relative contributions of CA, SA, APHV, pubertal stage, years of training in soccer, height, body mass, and sitting height to the variance of $\mathrm{VO}_{2}$ peak values. This protocol allowed all these independent variables to be entered into the regression equation and sequential removal of these variables that met the criteria for elimination [4]. Statistical significance was set at $\mathrm{p}<0.05$.

\section{RESULTS}

The participants` physical characteristics classified by skeletal maturity as LM, $\mathrm{AM}$ and EM groups are presented in Table 1. SA approximates CA in AM soccer players. In comparison with AM group, SA - CA difference was significantly $(\mathrm{p}<0.05)$ lower and higher in LM and EM groups, respectively. Soccer players classified as EM (14\%) were disproportionately represented in comparison with AM (41\%) and LM (45\%) groups. The distribution of Tanner stages in groups classified by skeletal maturity were quite similar. Tanner stages $1-3$ were represented among soccer players with different skeletal maturation, most of the soccer players being in Tanner stage $2-3$ in LM ( $n=25 ; 86 \%)$ AM ( $n=21$; 
$81 \%)$ and EM ( $\mathrm{n}=8 ; 89 \%)$ groups. Only $4(14 \%), 5$ (19\%) and 1 (11\%) boys were prepubertal in Tanner stage 1 among LM, AM and EM soccer players, respectively. EM soccer players had significantly $(\mathrm{p}<0.05)$ longer segment lengths and were heavier than less mature boys. Differences $(\mathrm{p}<0.05)$ in body mass among the groups justified the use of the allometric model.

Table 1. Mean $( \pm S D)$ physical characteristics of young soccer players in different skeletal maturity groups.

\begin{tabular}{lccc}
\hline \multicolumn{1}{c}{ Mean \pm SD } & $\begin{array}{c}\text { LM group } \\
(\mathbf{n}=\mathbf{2 9})\end{array}$ & $\begin{array}{c}\text { AM group } \\
(\mathbf{n}=\mathbf{2 6})\end{array}$ & $\begin{array}{c}\text { EM group } \\
(\mathbf{n}=\mathbf{9})\end{array}$ \\
\hline CA $(\mathrm{yrs})$ & $11.40 \pm 0.81$ & $11.21 \pm 0.74$ & $10.79 \pm 0.62^{*}$ \\
\hline SA (yrs) & $10.34 \pm 0.91$ & $11.22 \pm 0.75^{*}$ & $11.78 \pm 0.69^{*}$ \\
\hline SA - CA (yrs) & $-1.03 \pm 0.44$ & $0.01 \pm 0.29^{*}$ & $1.10 \pm 0.71^{*} \#$ \\
\hline APHV (yrs) & $13.68 \pm 0.44$ & $13.36 \pm 0.45^{*}$ & $12.93 \pm 0.51^{\star} \#$ \\
\hline Years to APHV (yrs) & $2.27 \pm 0.64$ & $2.15 \pm 0.53$ & $2.14 \pm 0.35$ \\
\hline Years of training (yrs) & $4.69 \pm 1.44$ & $4.42 \pm 1.60$ & $4.11 \pm 1.45$ \\
\hline Tanner stage & $2.03 \pm 0.57$ & $1.96 \pm 0.60$ & $2.22 \pm 0.66$ \\
(1/2/3/4/5) & $4 / 20 / 5 / 0 / 0$ & $5 / 17 / 4 / 0 / 0$ & $1 / 5 / 3 / 0 / 0$ \\
\hline Height (cm) & $146.45 \pm 7.31$ & $149.54 \pm 6.76$ & $150.56 \pm 4.88$ \\
\hline Body mass (kg) & $36.61 \pm 5.90$ & $38.98 \pm 5.82$ & $42.72 \pm 5.85^{*}$ \\
\hline Sitting height (cm) & $76.12 \pm 3.49$ & $77.87 \pm 2.93^{*}$ & $79.11 \pm 2.43^{*}$ \\
\hline Sitting height ratio $(\%)$ & $52.00 \pm 0.95$ & $52.10 \pm 1.26$ & $52.56 \pm 1.07$ \\
\hline
\end{tabular}

Note: LM group, late maturing group; AM group, average maturing group; EM, early maturing group; CA, calendar age; SA, skeletal age; APHV, age at predicted height velocity. *Significantly different from LM group; $p<.05$. \#Significantly different from AM group; $p<0.05$.

Peak oxygen consumption was not directly proportional to body mass as the experimentally observed exponent for body mass calculated through linear regression analysis yielded to $b=0.64$ for the studied young soccer players. However, it should be noted that the $95 \%$ confidence interval for the experimentally calculated body mass-related exponent (95\% CI: 0.51 to 0.77 ) included the theoretical values of the exponents $(b=0.67$ and $b=0.75)$. The adjusted coefficient of determination for this model was $\mathrm{R}^{2}=0.62(\mathrm{p}<0.05)$. Figure 1 demonstrates the test of independence for $\mathrm{VO}_{2}$ peak and body mass expressed as absolute value $(\mathrm{A})$, as a ratio standard (B), after applying theoretical exponents $b=0.67(C)$ and $b=0.75(D)$, and also experimentally observed exponent $b=0.64(E)$ for young soccer players. Based on the data presented in Figure 1, the experimentally observed exponent was superior to the theoretical exponents followed by the ratio standard by adjusting for the effects of body mass on $\mathrm{VO}_{2}$ peak in 10-12-year-old soccer players. 

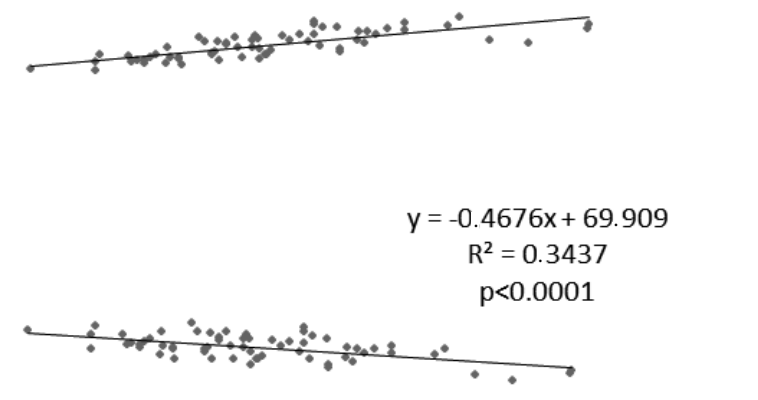

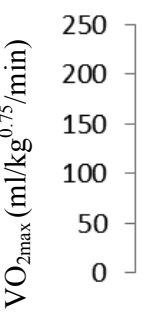

$$
\begin{gathered}
y=-0.3794 x+143.33 \\
R^{2}=0.0508
\end{gathered}
$$$$
\mathrm{p}=0.073
$$
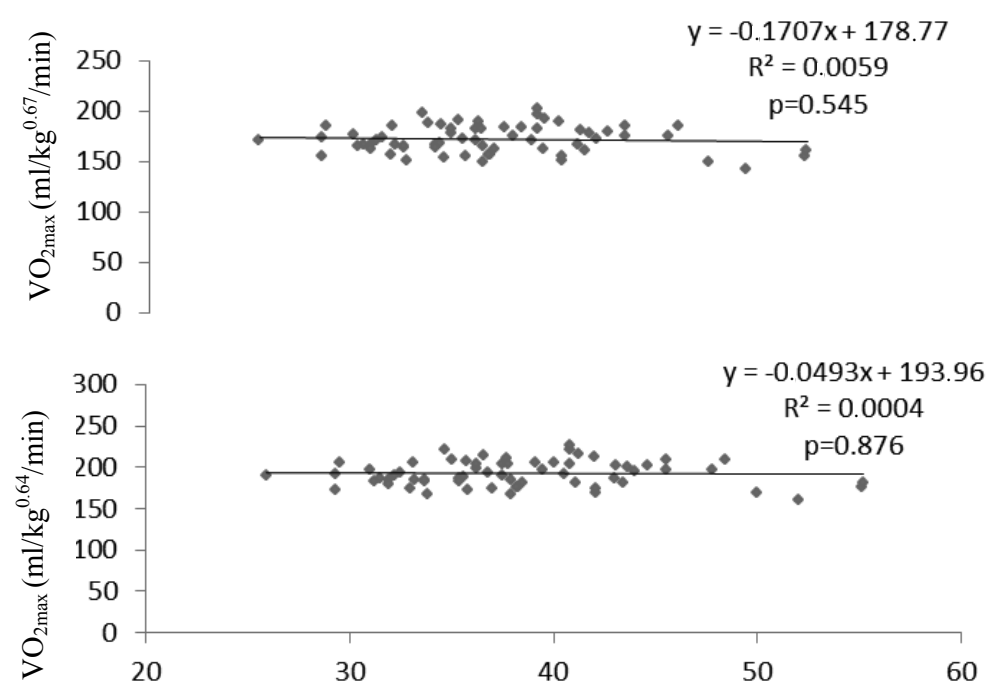

Body mass (kg)

Figure 1. Test of independence for $\mathrm{VO}_{2 \max }$ and body mass $(\mathrm{kg})$ expressed as absolute values $(A)$ and ratio standards $(B)$, after applying theoretical exponents $b=0.67(C)$ and $b=0.75(D)$, as well as experimentally observed exponent $b=0.64$ for 10-12-year-old soccer players. 
Tables 2, 3 and 4 demonstrate the five forms of expression of $\mathrm{VO}_{2}$ peak in young soccer players when grouped according to different skeletal maturity, CA and pubertal stage values, respectively. The absolute values $(1 / \mathrm{min})$ differed $(\mathrm{p}<0.05)$ between EM and LM groups (Table 2), 10-yrs-old and 12-yrs-old groups (Table 3) as well as pubertal stage I and pubertal stage III groups (Table 4$)$. In addition, $\mathrm{VO}_{2}$ peak $(1 / \mathrm{min})$ was significantly different in young soccer players between pubertal stages II and III. When $\mathrm{VO}_{2}$ peak values were adjusted for body mass $(\mathrm{ml} / \mathrm{kg} / \mathrm{min})$, or when the effects of body mass values were adjusted for using theoretical exponent scales $\left(\mathrm{ml} / \mathrm{kg}^{0.67} / \mathrm{min}\right.$, $\mathrm{ml} / \mathrm{kg}^{0.75} / \mathrm{min}$ ) and experimentally observed exponent $\left(\mathrm{ml} / \mathrm{kg}^{0.64} / \mathrm{min}\right)$, the $\mathrm{VO}_{2}$ peak responses did not increase ( $\mathrm{p}>0.05$ ) proportional to skeletal maturation levels, CA or pubertal stages, but displayed relatively constant values throughout different groups. The only exception was when $\mathrm{VO}_{2}$ peak was adjusted for experimentally observed exponent $\left(\mathrm{ml} / \mathrm{kg}^{0.64} / \mathrm{min}\right)$, where young soccer players in pubertal stage III had significantly higher $(\mathrm{p}<0.05) \mathrm{VO}_{2}$ peak values in comparison with pubertal stage I soccer players.

Table 2. Mean ( $\pm \mathrm{SD})$ peak oxygen consumption $\left(\mathrm{VO}_{2}\right.$ peak) values in young soccer players in different skeletal maturity groups.

\begin{tabular}{lccc}
\hline Mean \pm SD & $\begin{array}{c}\text { LM group } \\
(\mathbf{n}=\mathbf{2 9})\end{array}$ & $\begin{array}{c}\text { AM group } \\
(\mathbf{n = 2 6})\end{array}$ & $\begin{array}{c}\text { EM group } \\
(\mathbf{n}=\mathbf{9})\end{array}$ \\
\hline $\mathrm{VO}_{2}$ peak $(\mathrm{l} / \mathrm{min})$ & $1.89 \pm 0.24$ & $2.02 \pm 0.24$ & $2.14 \pm 0.24^{*}$ \\
\hline $\mathrm{VO}_{2}$ peak $(\mathrm{ml} / \mathrm{kg} / \mathrm{min})$ & $52.26 \pm 5.27$ & $52.11 \pm 4.43$ & $50.40 \pm 5.12$ \\
\hline $\mathrm{VO}_{2}$ peak $\left(\mathrm{ml} / \mathrm{kg}^{0.75} / \mathrm{min}\right)$ & $127.95 \pm 10.77$ & $129.75 \pm 9.66$ & $128.47 \pm 11.57$ \\
\hline $\mathrm{VO}_{2}$ peak $\left(\mathrm{ml} / \mathrm{kg}^{0.67} / \mathrm{min}\right)$ & $170.46 \pm 13.98$ & $173.78 \pm 12.84$ & $173.34 \pm 15.28$ \\
\hline $\mathrm{VO}_{2}$ peak $\left(\mathrm{ml} / \mathrm{kg}^{0.64} / \mathrm{min}\right)$ & $189.82 \pm 15.49$ & $193.91 \pm 14.36$ & $193.96 \pm 17.01$ \\
\hline
\end{tabular}

Note: LM group, late maturing group; AM group, average maturing group; EM, early maturing group. * Significantly different from LM group; $p<0.05$.

Table 3. Mean $( \pm \mathrm{SD})$ peak oxygen consumption $\left(\mathrm{VO}_{2}\right.$ peak) values in young soccer players in different chronological age groups.

\begin{tabular}{lccc}
\hline \multicolumn{1}{c}{ Mean \pm SD } & $\begin{array}{c}\text { 10-yrs-old } \\
(\mathbf{n = 2 4 )}\end{array}$ & $\begin{array}{c}\text { 11-yrs-old } \\
(\mathbf{n}=27)\end{array}$ & $\begin{array}{c}\text { 12-yrs-old } \\
(\mathbf{n}=\mathbf{1 3})\end{array}$ \\
\hline $\mathrm{VO}_{2}$ peak $(\mathrm{l} / \mathrm{min})$ & $1.90 \pm 0.29$ & $2.00 \pm 0.23$ & $2.08 \pm 0.18^{*}$ \\
\hline $\mathrm{VO}_{2}$ peak $(\mathrm{ml} / \mathrm{kg} / \mathrm{min})$ & $52.41 \pm 4.21$ & $51.45 \pm 4.21$ & $52.08 \pm 5.82$ \\
\hline $\mathrm{VO}_{2}$ peak $\left(\mathrm{ml} / \mathrm{kg}^{0.75} / \mathrm{min}\right)$ & $128.33 \pm 9.16$ & $128.20 \pm 10.63$ & $130.69 \pm 12.13$ \\
\hline $\mathrm{VO}_{2}$ peak $\left(\mathrm{ml} / \mathrm{kg}^{0.67} / \mathrm{min}\right)$ & $170.98 \pm 12.59$ & $171.74 \pm 13.79$ & $175.46 \pm 15.42$ \\
\hline $\mathrm{VO}_{2}$ peak $\left(\mathrm{ml} / \mathrm{kg}^{0.64} / \mathrm{min}\right)$ & $190.42 \pm 14.31$ & $191.65 \pm 15.27$ & $195.96 \pm 16.90$ \\
\hline
\end{tabular}

Note: *Significantly different from 10-yrs-old group; $p<0.05$. 
Table 4. Mean $( \pm \mathrm{SD})$ peak oxygen consumption $\left(\mathrm{VO}_{2}\right.$ peak) values in young soccer players in different pubertal stage groups.

\begin{tabular}{lccc}
\hline Mean $\pm \mathrm{SD}$ & $\begin{array}{c}\text { Pubertal stage I } \\
(\mathbf{n}=\mathbf{1 0})\end{array}$ & $\begin{array}{c}\text { Pubertal stage II } \\
(\mathbf{n}=\mathbf{4 2})\end{array}$ & $\begin{array}{c}\text { Pubertal stage III } \\
(\mathbf{n}=\mathbf{1 2})\end{array}$ \\
\hline $\mathrm{VO}_{2}$ peak $(\mathrm{I} / \mathrm{min})$ & $1.83 \pm 0.23$ & $1.96 \pm 0.24$ & $2.17 \pm 0.20^{*} \#$ \\
\hline $\mathrm{VO}_{2}$ peak $(\mathrm{ml} / \mathrm{kg} / \mathrm{min})$ & $51.62 \pm 3.78$ & $51.99 \pm 5.34$ & $52.03 \pm 4.30$ \\
\hline $\mathrm{VO}_{2}$ peak $\left(\mathrm{ml} / \mathrm{kg}^{0.75} / \mathrm{min}\right)$ & $125.72 \pm 7.99$ & $128.52 \pm 10.94$ & $132.12 \pm 9.48$ \\
\hline $\mathrm{VO}_{2}$ peak $\left(\mathrm{ml} / \mathrm{kg}^{0.67} / \mathrm{min}\right)$ & $167.19 \pm 10.75$ & $171.74 \pm 14.14$ & $178.05 \pm 12.49$ \\
$\mathrm{VO}_{2}$ peak $\left(\mathrm{ml} / \mathrm{kg}^{0.64} / \mathrm{min}\right)$ & $186.06 \pm 12.11$ & $191.47 \pm 15.65$ & $199.13 \pm 13.91^{*}$ \\
\hline
\end{tabular}

Note: "Significantly different from Pubertal stage I; $p<.05$; "Significantly different from Pubertal stage II; $p<0.05$.

Correlational anaylsis demonstrated that $\mathrm{VO}_{2}$ peak $(1 / \mathrm{min})$ was related $(\mathrm{p}<0.05)$ to CA $(\mathrm{r}=0.28)$, pubertal stage $(\mathrm{r}=0.43)$, height $(\mathrm{r}=0.64)$, body mass $(\mathrm{r}=0.80)$, BMI $(\mathrm{r}=0.55)$ and sitting height $(\mathrm{r}=0.63)$ values. In addition, different body size parameters were also related $(\mathrm{p}<0.05)$ to $\mathrm{VO}_{2}$ peak, when expressed as ratio standard for body mass $(\mathrm{ml} / \mathrm{min} / \mathrm{kg})$ : height $(\mathrm{r}=-0.25)$, body mass $(\mathrm{r}=-0.48)$, BMI $(\mathrm{r}=-0.37)$ and sitting height $(\mathrm{r}=-0.25)$. In contrast, no significant relationship $(\mathrm{p}>0.05)$ between measured biological maturation and body size values with $\mathrm{VO}_{2}$ peak were observed, when $\mathrm{VO}_{2}$ peak was adjusted for theoretical exponent scale of body mass $b=0.67(r<0.24 ; p>0.05)$ and $b=0.75(r<0.18 ; p>0.05)$. When the effect of body mass was adjusted for using experimentally observed exponent scales $b=0.64, \mathrm{VO}_{2}$ peak was only correlated with pubertal stage $(r=0.26 ; \mathrm{p}<0.05)$ in young soccer players.

The results of the multiple linear regression analyses to compare the relative contributions of CA, SA, APHV, pubertal stage, years of training in soccer, height, body mass, and sitting height to the variance of the five forms of expression of $\mathrm{VO}_{2}$ peak used in this study showed that body mass was the most important parameter influencing $\mathrm{VO}_{2}$ peak when expressed as absolute value $(1 / \mathrm{min})$ or simple ratio standard $(\mathrm{ml} / \mathrm{kg} / \mathrm{min})$ in 10 -to-12-year-old soccer players (Table 5). However, after adjusting for the effects of body mass using the theoretical exponent scales $\left(\mathrm{ml} / \mathrm{kg}^{0.67} / \mathrm{min}\right.$ and $\left.\mathrm{ml} / \mathrm{kg}^{0.75} / \mathrm{min}\right)$, the used biological maturation and body size values had no effect on $\mathrm{VO}_{2}$ peak in young soccer players. In contrast, when the experimentally observed exponent $\left(\mathrm{ml} / \mathrm{kg}^{0.64} / \mathrm{min}\right)$ for body mass was used to adjust for $\mathrm{VO}_{2}$ peak, pubertal stage had a significant effect on $\mathrm{VO}_{2}$ peak value in young soccer players. 
Table 5. Results of stepwise multiple linear regression analysis with peak oxygen consuption $\left(\mathrm{VO}_{2}\right.$ peak) as dependent variable and chronological age, skeletal age, age at peak height velocity, Tanner stage, years of training in soccer, height, body mass, body mass index and sitting height as independent variables $\left(R^{2} \times 100\right.$; $\mathrm{p}<0.05)$.

\begin{tabular}{lccccc}
\hline Dependent variables & $\begin{array}{c}\text { Independent } \\
\text { variables }\end{array}$ & $\begin{array}{c}\text { Standardized } \\
\beta \text { coefficent }\end{array}$ & $\mathbf{R}^{2}$ & $\mathbf{R}^{2}$ adjusted & $\mathbf{p}$ \\
\hline $\mathrm{VO}_{2}$ peak $(\mathrm{l} / \mathrm{min})$ & Body mass & 0.76 & 0.58 & 0.57 & 0.000 \\
\hline $\mathrm{VO}_{2}$ peak $(\mathrm{ml} / \mathrm{kg} / \mathrm{min})$ & Body mass & -0.59 & 0.34 & 0.33 & 0.000 \\
\hline $\mathrm{VO}_{2}$ peak $\left(\mathrm{ml} / \mathrm{kg}^{0.67} / \mathrm{min}\right)$ & - & - & - & - & - \\
\hline $\mathrm{VO}_{2}$ peak $\left(\mathrm{ml} / \mathrm{kg}^{0.75} / \mathrm{min}\right)$ & - & - & - & - & - \\
\hline $\mathrm{VO}_{2}$ peak $\left(\mathrm{ml} / \mathrm{kg}^{0.64} / \mathrm{min}\right)$ & $\begin{array}{c}\text { Pubertal } \\
\text { stage }\end{array}$ & 0.26 & 0.07 & 0.05 & 0.040 \\
\hline
\end{tabular}

\section{DISCUSSION}

This study was untertaken to assess the effect of biological maturation and body size parameters on aerobic capacity in young soccer players. To our best of knowledge, this is the first study to demonstrate that biological maturation and body size do not affect $\mathrm{VO}_{2}$ peak values in 10-12-year-old soccer players when proper scaling procedure has been used. The results of present study indicate that the theoretical exponent scales for body mass $\left(\mathrm{ml} / \mathrm{kg}^{0.67} / \mathrm{min}\right.$ and $\mathrm{ml} / \mathrm{kg}^{0.75} / \mathrm{min}$ ) control adequately for biological maturation and body size differences in $\mathrm{VO}_{2}$ peak in 10-12-year-old soccer players. Therefore, $\mathrm{VO}_{2}$ peak values when expressed as traditional ratio standards or theoretical exponent scales for body mass were not significantly different between young soccer players with contrasting skeletal maturity status, CA or pubertal stages. Accordingly, $\mathrm{VO}_{2}$ peak does not differ among trained 10-12-year-old young soccer players with different maturity classifications and more mature soccer players with greater body size values should not be preferentially selected.

The results of present study showed that LM $(n=29)$ and AM $(n=26)$ soccer players were similarly represented, while EM $(n=9)$ were under-represented among 10-12-year-old boys participating in young soccer teams. This demonstrates that no further selection according to advanced skeletal maturity has not yet been done in this relatively young age group. In comparison, late, on time and early maturing soccer players were similarly represented among 11-12-year-olds, while late maturing boys were already under-represented among 13-14-year-olds [5, 12]. Another finding of the present study was that pubertal development according to Tanner stages did not differ among LM, $\mathrm{AM}$ and EM soccer players, indicating that more than $80 \%$ of the boys studied 
were in pubertal stages $2-3$ in all three skeletal maturity groups. Other studies have reported more variation in pubertal stages in young soccer players with contrasting skeletal maturity status $[5,12]$. Specifically, among 11-12-yearold soccer players, most LM boys were prepubertal (pubertal stage $1 ; 88 \%$ ), while pubertal stages 1-3 were represented in AM and EM groups of young soccer players $[5,12]$. However, it has to be taken into account that Tanner stage shows specific pubertal stage at the time of examination and does not provide further knowledge when young soccer player entered into the specific pubertal stage or how long he has been in this specific pubertal stage [12]. While pubertal status according to Tanner stage is an indicator of maturity status, SA-CA and APHV are indicators of maturity timing [12]. Accordingly, different results of present study and that of previous studies $[5,12]$ could be explained by the fact that years to APHV were not different $(p>0.05)$ among soccer players with contrasting skeletal maturity status in the present study. In addition, APHV values in our soccer players with contrasting skeletal maturity status were comparable for Flemish young soccer players (13.8 \pm 0.8 yrs) [16] suggesting similar maturity timing. Therefore, it has been suggested that APHV can widely be used in studies with athletes and is increasingly used by various English professional soccer clubs to estimate maturity timing in academy players, although this value has some limitations for classifying young soccer players as early, average and late maturing [12]. Taken together, according to our results, it could be suggested that less mature soccer players are well represented among 10-12-year-old Estonian soccer players and there is no evidence for preferential selection of more mature soccer players at this relatively young age group.

More mature children in young soccer players had advantages over late maturing children in measured body size characteristics (BMI, body mass, sitting height). Variation in body size that is associated with contrasting maturity status in young soccer players was similar to other studies with young soccer players, among whom soccer players advanced in skeletal maturity are taller and heavier than those on time and late in skeletal maturity $[6,12,14,16]$. This in turn may influence different physiological performance parameters in young soccer players as the beneficial effects of biological maturation on different endurance variables in pubertal soccer players have previosly been described $[4,5]$. Accordingly, $\mathrm{VO}_{2}$ peak expressed in absolute values $(1 / \mathrm{min})$ differed $(\mathrm{p}<0.05)$ between EM and LM groups (Table 2) as well as between 10-yrsold and 12-yrs-old groups (Table 3 ) and pubertal stage I and pubertal stage III groups (Table 4). Increases in $\mathrm{VO}_{2}$ peak are highly related to increases in body mass values [18] and consequently $\mathrm{VO}_{2}$ peak when expressed in absolute values 
( $1 / \mathrm{min})$ increase proportionally with biological development [4]. However, when $\mathrm{VO}_{2}$ peak values are expressed as ratio standards to body mass values, $\mathrm{VO}_{2}$ peak responses do not increase proportionally with biological maturation, showing a rather constant pattern in young soccer players with contrating maturational timing $[4,19]$. This was also the case in our young soccer players entering puberty. In accordance, Figuiredo et al. [6] demonstrated that body size and strength discrepancies among 11-12-year-old soccer players with contrasting maturity status were not a major advantage to soccer performance as these soccer players did not differ consistently in aerobic endurance and in soccerspecific skills. It was concluded that smaller and less mature players should be provided equal opportunities in soccer also during the adolescent years [6].

It has been suggested that $\mathrm{VO}_{2}$ peak should be expressed in relation to body mass raised to the power of $0.72-0.94$ over a wide range of body mass depending on the group investigated [3]. A recent study observed that biological maturation and body size did not affect $\mathrm{VO}_{2}$ peak values in a heterogeneous group of 12-19 years old young soccer players when experimentally observed exponent $\mathrm{b}=0.90$ was applied [4]. Cunha et al. [4] concluded that it was inappropriate to use traditional ratio standard $(\mathrm{ml} / \mathrm{min} / \mathrm{kg})$ or theoretical exponent scales $\left(\mathrm{ml} / \mathrm{kg}^{0.67} / \mathrm{min}\right.$ and $\left.\mathrm{ml} / \mathrm{kg}^{0.75} / \mathrm{min}\right)$ for body mass when assessing $\mathrm{VO}_{2}$ peak in these young soccer players. In contrast to Cunha et al. [4] study, multiple linear regression analyses in our study demonstrated that body size and biological maturation were not associated with $\mathrm{VO}_{2}$ peak values when theoretical scaling exponents $\left(\mathrm{ml} / \mathrm{kg}^{0.67} / \mathrm{min}\right.$ and $\left.\mathrm{ml} / \mathrm{kg}^{0.75} / \mathrm{min}\right)$ were used in a relatively homogeneous age group of young soccer players (see Table 5). It has to be taken into account that the more widely used traditional ratio standard and theoretical exponent scales allow for the comparison between different studies. However, when $\mathrm{VO}_{2}$ peak values were expressed using experimentally observed exponent $b=0.64$ to adjust for the body mass in our 10-12-year-old soccer players, young soccer players in pubertal stage III had significantly higher $\mathrm{VO}_{2}$ peak values in comparison with young soccer players in pubertal stage I (see Table 4) and pubertal stage was the predictive variable for variance in $\mathrm{VO}_{2}$ peak $\left(\mathrm{ml} / \mathrm{kg}^{0.64} / \mathrm{min}: 5 \% ; \mathrm{p}<0.001\right.$ ) (see Table 5). This suggested that maturity stage but not maturity timing had some effect on $\mathrm{VO}_{2}$ peak values in 10-12-year-old soccer players. In support to our results, Chamari et al. [3] found that 14-yearold soccer players had significantly lower $\mathrm{VO}_{2}$ peak values in comparison with senior players, when expressed according to the experimentally observed exponent scale $b=0.72$. However, calculating the $\mathrm{VO}_{2}$ peak data using theoretical scaling component $b=0.75$ gave identical conclusion [3]. In our study, it should be noted that the $95 \%$ confidence interval for the experimentally 
calculated body mass-related exponent $b=0.64$ ( $95 \%$ CI: 0.51 to 0.77 ) included the theoretical values of the exponents $(b=0.67$ and $b=0.75)$ in young soccer players. In addition, although the experimentally observed exponent $(b=0.64$ : $\left.\mathrm{R}^{2}=0.0004 ; \mathrm{p}=0.876\right)$ was superior to the theoretical exponents $(\mathrm{b}=0.67$ : $\mathrm{R}^{2}=0.059 ; \mathrm{p}=0.545$ and $\mathrm{b}=0.75: \mathrm{R}^{2}=0.0508 ; \mathrm{p}=0.073$ ) by adjusting for the effects of body mass on $\mathrm{VO}_{2}$ peak in 10-12-year-old soccer players (see Figure 1 ), the theoretical exponent of $b=0.67$ for body mass also showed clear independence between $\mathrm{VO}_{2}$ peak and body mass in our young soccer players entering puberty. Taken together, the widely used theoretical exponent of $b=0.67$ for $\mathrm{VO}_{2}$ peak will control adequately for body size differences and allows for the comparsion with the results of other studies in our young soccer players.

In summary, routine testing and selection procedure is easier and more widely used when it is based on chronological age. However, possible differences in performance in soccer should be analysed carefully as individuals of the same chronological age may show large variations in maturational time and tempo, which can affect talent identification in soccer. The results of the present study demonstrate the importance to use appropriate scaling procedures to express $\mathrm{VO}_{2}$ peak values in subjects who differ in biological maturation and body size variables. From a practical point of view, it is not necessary to calculate experimentally observed exponents, which does not allow for the comparison of the results of other studies in a relatively young age group of 10-12-years-old soccer players. It appears that the theoretical exponent scale for body mass $\left(\mathrm{ml} / \mathrm{kg}^{0.67} / \mathrm{min}\right)$ is appropriate measure to expresss $\mathrm{VO}_{2}$ peak in peripubertal soccer players.

\section{ACKNOWLEDGMENTS}

This study was supported by the Estonian Ministry of Education grant TKKSP 0489.

\section{REFERENCES}

1. Armstrong N, Welsman JR. (2000) Development of aerobic fitness during childhood andadolescence. Ped Exerc Sci, 12: 128-149

2. Baxter-Jones ADG, Sherar LB. (2007) Growth and maturation. In: Armstrong $\mathrm{N}$ (ed). Advances in Sport and Exercise Science Series. Paediatric Exercise Physiology. Elsevier Limited, 1-26 
3. Chamari K, Moussa-Chamari I, Boussaidi L, Hachana Y, Kaouech F, Wisloff U. (2005) Appropriate interpretation of aerobic capacity: allometric scaling in adult and young soccer players. Br J Sports Med, 3: 97-101

4. Cunha G, Lorenzi T, Sapata K, Lopes AL, Gaya AC, Oliveira A. (2011) Effect of biological maturation on maximal oxygen uptake and ventilatory thresholds in soccer players: an allometric approach. J Sports Sci, 29: 1029-1039

5. Figueiredo AJ, Goncalves CE, Coelho e Silva MJ, Malina RM. (2009) Youth soccer players, 11-14 years: maturity, size, function, skill and goal orientation. Ann Hum Biol, 36: 60-73

6. Figueiredo AJ, Coelho e Silva MJ, Cumming SP, Malina RM. (2010) Size and maturity mismatch in youth soccer players 11- to 14-years-old. Ped Exerc Sci, 22: 596-612

7. Greulich WW, Pyle SI. (1959) Radiographics Atlas of Skeletal Development of Hand and Wrist. 2nd edn. Stanford University Press, Palo Alto

8. Hoff J, Wisloff U, Engen LC, Kemi OJ, Helgerud J. (2002) Soccer specific aerobic endurance training. Br J Sports Med, 36: 218-221

9. Jürimäe J, Haljaste K, Cicchella A, Lätt E, Purge P, Leppik A, Jürimäe T. (2007) Analysis of swimming performance from physical, physiological, and biomechanical parameters in young swimmers. Ped Exerc Sci, 19: 70-82

10. Malina RM, Eisenmann JC, Cumming SP, Ribeiro B, Aroso J. (2004) Maturityassociated variation in the growth and functional capacities of youth football (soccer) players aged 13-15 years. Eur J Appl Physiol, 91: 555-562

11. Malina RM, Cumming SP, Kontos AP, Eisenmann JC, Ribeiro B, Aroso J. (2005) Maturity-associated variation in sport-specific skills of youth soccer players aged 13-15. J Sports Sci, 23: 515-522

12. Malina RM, Coelho e Silva MJ, Figueiredo AJ, Carling C, Beunen GP. (2012) Interrelationships among invasive and non-invasive indicators of biological maturation in adolescent male soccer players. J Sports Sci, 30: 1705-1717

13. Matsudo SMM, Matsudo VKK. (1994) Self assessment and physician assesment of sexual maturation in Brazilian boys and girls: concordance and reproducibility. Am J Hum Biol, 6: 451-455

14. Mendez-Villanueva A, Buchheit M, Kuitunen S, Douglas A, Peltola E, Bourdon P. (2011) Age-related differences in acceleration, maximum running speed, and repeated-sprint performance in young soccer players. J Sport Sci, 29: 477-484

15. Pettersen SA, Fredriksen PM, Ingjer E. (2001) The correlation between peak oxygen uptake $\left(\mathrm{VO}_{2}\right.$ peak) and running performance in children and adolescents. Aspects of different units. Scand J Med Sci Sports, 11: 223-228

16. Philippaerts RM, Vaeyens R, Janssens M, van Renterghem B, Matthys D, Craen R, Bourgois J, Vrijens J, Beunen G, Malina RM. (2006) The relationship between peak height velocity and physical performance in youth soccer players. J Sports Sci, 24: 221-230

17. Pomerants T, Tillmann V, Karelson K, Jürimäe J, Jürimäe T. (2006) Ghrelin response to acute aerobic exercise in boys at different stages of puberty. Horm Metab Res, 38: 752-757 
18. Rowland TW. (2005) Children's Exercise Physiology. 2nd end. Champaign, IL: Human Kinetics

19. Segers V, De Clercq D, Janssens M, Bourgois J, Philippaerts R. (2008) Running economy in early and late maturing youth soccer players does not differ. $\mathrm{Br}$ J Sports Med, 42: 289-294

20. Tanner J. (1962) Growth at Adol. 2nd edn. Blackwell, Oxford

\section{Correspondence to:}

Jaak Jürimäe

Chair of Coaching Sciences

Institute of Sport Pedagogy and Coaching Sciences

University of Tartu

Ülikooli 18

Tartu 50090

ESTONIA

E-mail: jaak.jurimae@ut.ee 